\title{
Synthesis of Zinc Fluoroborate by Wet Method and Its Application as a
}

\section{Flame Retardant for Cotton Fabrics}

\section{DOI : 10.36909/jer.12315}

\author{
Duygu Y1lmaz Aydın* and Metin Gürü** \\ * Department of Bioengineering, Faculty of Engineering and Natural Sciences, Malatya Turgut \\ Ozal University, Malatya, Turkey \\ ${ }^{* *}$ Department of Chemical Engineering, Faculty of Engineering, Gazi University, Ankara, \\ Turkey
}

Corresponding Author: duygu.aydin@ozal.edu.tr

\begin{abstract}
In this study, zinc fluoroborate was synthesized by wet method using fluoroboric acid and zinc oxide as reactant and its usability as flame retardant for cotton fabrics was investigated. The wet method is economical, green, efficient and applicable for a large-scale. The maximum yield was determined related to the variation of reactant ratio, temperature, reaction period and stirrer rate. The characterization of the product was carried out by means of FTIR, $\mathrm{BF}_{4}{ }^{-}$ion selective electrode and XRD. The maximum yield of $97 \%$ was achieved at the reactant mole ratio $\left(\mathrm{nZnO} / \mathrm{nHBF}_{4}\right)$ of $1: 3$, temperature of $90{ }^{\circ} \mathrm{C}$ and reaction period of 90 minutes. The purity of the synthesized product was found as $98 \%$. Flame retardancy and high temperature resistance effects of zinc fluoroborate on cotton fabrics were investigated by LOI test and high temperature durability test method, respectively. Although LOI value of the untreated original fabric was determined as 16 , this value increased above 55 by impregnating of fabric with $50 \%$ zinc fluoroborate solution.
\end{abstract}

KEYWORDS: Zinc fluoroborate; Zinc oxide; Fluoroboric acid; Flame retardant 


\section{INTRODUCTION}

Developing novel flame-retardants is an important research issue. Many types of fire retardants have been developed and made available commercially; they are phosphorus, silicon, boron, nitrogen and miscellaneous elements based fire retardants. Flame-retardants move in the vapor phase or in the condensed phase via chemical or physical mechanisms to interfere with combustion during heating, pyrolysis, ignition or flame spreading (Lu and Hamerton, 2002). The flame retardant property of boron compounds relates to the formation of a surface protective coal layer that acts as a barrier to prevent carbon oxidation. An acceptable fire retardant composition for the treatment of textile substrates must be non-toxic. For environmental reasons, the use of halogen-containing flame-retardants should be reduced. Boron containing flame-retardants are cheaper, less toxic alternatives according to traditional flame-retardants such as halogen-containing flame-retardants (Lu and Hamerton, 2002). Boron compounds that are active in the condensed phase are significant family of inorganic additives with flame retardant properties and considered as environmentally friendly when they are used as flame-retardants (Dogan and Unlu, 2014; Wang et al., 2010). They are also used in smoke suppression, promoting charring, and multifunctional flame-retardants such as pigment in dye (Ayar et al., 2014).

Actually, fluoroborates are one of the special boron compounds, which can be used flame retardant. The first scientific study on fluoroborates, salts of tetrafluoroboric acid, was performed by Berzelius (Booth and Martin, 1949). The compounds involved in this group are alkali metal tetrafluoroborates, ammonium tetrafluoroborate and transition element tetrafluoroborates. To obtain expensive special boron compounds from cheap boron sources is considerably important in terms of economic gains. Fluoroborates can be obtained using different methods such as wet method (Ceyhan et al., 2020) and mechanochemical method 
(Aydın et al., 2017; Aydın et al., 2019). The wet chemical synthesis method covers chemical reactions in the solution phase using reactants under appropriate experimental conditions. The wet chemical synthesis method is a very efficient, simple, fast, highly controllable, scalable and no purification step is required. Metal fluoroborates are produced by the wet method from the reaction of fluoroboric acid and metal salts or boric acid and hydrofluoric acid with metal salts (Papcun, 2000). Moreover, fluoroborates are commercially important to a variety of industries. Main group metal, transition and other heavy-metal fluoroborate salts and ammonium fluoroborates are used in different fields. Fluoroborates are used as catalysts, especially zinc fluoroborate is a versatile and robust catalyst for various organic reactions and transformations (Achilonu and Umesiobi, 2010; Sarkar et al., 2015; Pujala et al., 2011; Ranu et al., 1999). Lithium fluoroborate is used as an electrolyte in the lithium sulfur battery. The Li-ion cell using lithium fluoroborate based electrolyte is less moisture sensitive and shows much better performance at high temperature electrolyte (Zhang et al., 2002). Tetramethylammonium tetrafluoroborate is used in electrochemical double layer capacitors (Park and Kim, 2017). Fluoroborates are also used in glasses (Rayappan and Marimuthu, 2013). Zinc (Prajnashree et al., 2013), lead (Wagh et al., 2017), lithium (Ibrahim et al., 2016), sodium (Rayappan et al., 2010) etc. fluoroborate glasses when used with rare earth elements have good physical parameters and provide thermal stability against devitrification. Furthermore, tin, lead, methylimidazolium etc. fluoroborates are used electro plating baths (Liu and Pritzker, 2003; Chen et al., 1999). Fluoroborates increase flame resistance of material and reduce smoke. They are used as flame retardants in synthetic fibers, polymers (Wilkie and Morgan, 2009) textile materials etc. (Fidell and Brook, 1971; Kasem and Richard, 1972).

Some test methods for example thermogravimetric analysis, LOI analysis, UL-94 test, cone colorimeter test are used to evaluate the flammability of flame retardant materials (Bourbigot 
et al., 1999). In this study, LOI test was used as a flammability test method. The LOI test measures the required minimum oxygen concentration of a material to support combustion.

The purpose of this study was to synthesize zinc fluoroborate by wet method under optimum conditions and to investigate its performance against flame and high temperature in cotton fabrics.

\section{MATERIALS AND METHODS}

Zinc oxide (99\% pure, Sigma-Aldrich) and fluoroboric acid solution (50\% pure, Acros Organics) were used as reactants to synthesize zinc fluoroborate. High purity commercial zinc fluoroborate was purchased from Sigma- Aldrich (333875).

Experimental studies were carried out at different mole ratios, temperatures and stirring rates. The zinc fluoroborate crystals were obtained after filtration. Chemical reaction was shown in Eq. (1).

$\mathrm{ZnO}+2 \mathrm{HBF}_{4} \longrightarrow \mathrm{Zn}\left(\mathrm{BF}_{4}\right)_{2}+\mathrm{H}_{2} \mathrm{O}$

Fluoroborate ion concentration has been determined by fluoroborate ion selective electrode. Ion meter (S220) and $\mathrm{BF}_{4}^{-}$ion selective electrode (DX287) were supplied from Mettler Toledo (Figure 1). Synthetic and commercial zinc fluoroborate samples were tried to analyze by XRD instrument (Rigaku). The synthesized product was characterized by Fourier transform infrared spectroscopy (Jasco FTIR-480).

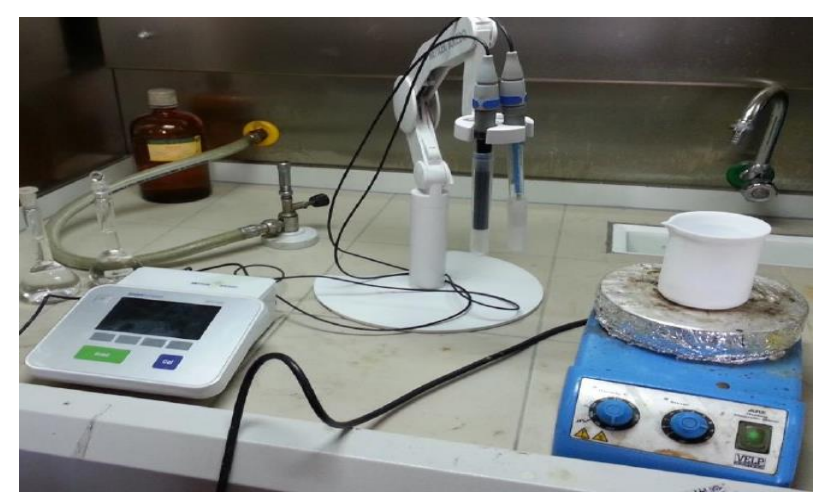


Figure 1. The view of experimental setup

Zinc fluoroborate solutions were prepared at different concentrations (15\%, 30\% and 50\%) for flame retarding tests. These solutions were impregnated into cotton fabrics. The fabrics remained in solution for 12 hours and dried in atmospheric environment. LOI (limit oxygen index) instrument (Dynisco) was utilized for flammability tests (Figure 2). Fabric properties were given in Table 1.

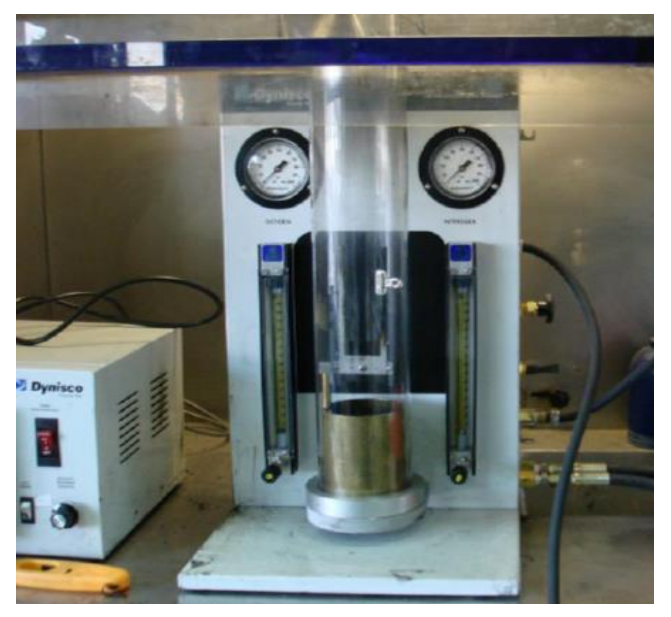

Figure 2. Limiting Oxygen Index (LOI) Chamber

Table 1. The properties of fabric used in experiments

\begin{tabular}{ll}
\hline Fiber type & $100 \%$ cotton \\
Weaving type & $2 \times 2$ \\
Areal density $(\mathrm{g} / \mathrm{m} 2)$ & 437 \\
Weft density (picks/cm) & 15 pieces \\
Waft density (ends/cm) & 23 pieces \\
\hline
\end{tabular}

High temperature laboratory furnace was used for high temperature durability tests. Original fabric and $50 \%$ zinc fluoroborate solution impregnated fabric stayed one hour at 120, 200, 250 ${ }^{\circ} \mathrm{C}$. 


\section{RESULTS AND DISCUSSION}

In experiments, the progress of the reaction was determined with the fluoroborate ion concentration in the reaction medium. The experiments were conducted at various mole ratios and temperatures. Optimum reactant mole ratio $\left(\mathrm{nHBF}_{4} / \mathrm{nZnO}\right)$ was determined by studying different reactant mole ratios $(1: 1,2: 1,3: 1,4: 1,5: 1)$. At first, the temperature and stirring rate were fixed $50{ }^{\circ} \mathrm{C}$ and $300 \mathrm{rpm}$, respectively. The reaction could not complete when mole ratio $\left(\mathrm{nHBF}_{4} / \mathrm{nZnO}\right)$ was $1: 1$. Figure 3 shows that when mole ratio of reactants are $3: 1$ and $4: 1$, the yield is almost same. In other words, the amount of product formed did not change at the end of the reaction when the reactant mole ratio $\left(\mathrm{nHBF}_{4} / \mathrm{nZnO}\right)$ was $3: 1$ and $4: 1$. The excess of fluoroboric acid did not change the amount of product formed after a certain amount. Zinc fluoroborate was produced with $67 \%$ yield at $50{ }^{\circ} \mathrm{C}$, reactant mole ratio $\left(\mathrm{nHBF}_{4} / \mathrm{nZnO}\right)$ of $3: 1$, and 300 rpm stirring rate.

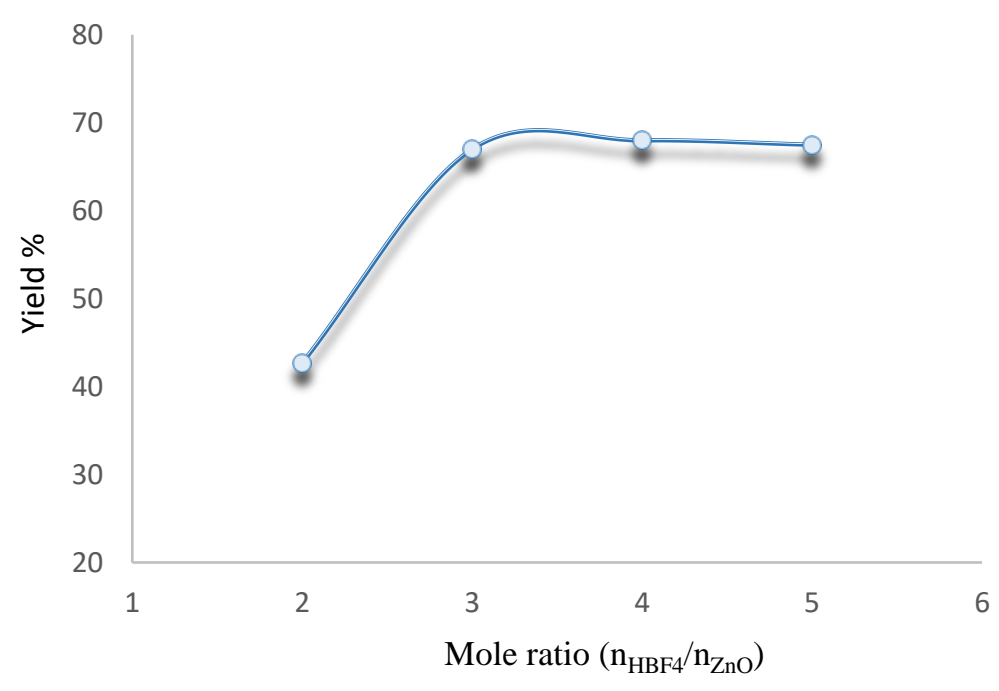

Figure 3. Effect of mole ratio $\left(\mathrm{nHBF}_{4} / \mathrm{nZnO}\right)$ on the product yield $\left(50{ }^{\circ} \mathrm{C}, 300 \mathrm{rpm}\right)$

Experiments were performed at different temperatures $\left(25^{\circ} \mathrm{C}, 50{ }^{\circ} \mathrm{C}, 70{ }^{\circ} \mathrm{C}, 90^{\circ} \mathrm{C}, 98^{\circ} \mathrm{C}\right)$ when stirring rate was $300 \mathrm{rpm}$ and mole ratio $\left(\mathrm{nHBF}_{4} / \mathrm{nZnO}\right)$ was fixed as 3:1. The yield was found using the amount of the product after reaction completed. Effect of temperature on the product yield was given in Figure 4. As can be seen in Figure 4, zinc fluoroborate production yield 
enhanced when the temperature increased up to $90{ }^{\circ} \mathrm{C}$. The amounts of product were almost same at $90^{\circ} \mathrm{C}$ and $98^{\circ} \mathrm{C}$. Since the amount of zinc fluoroborate formed as a result of the reaction carried out at $90{ }^{\circ} \mathrm{C}$ and $98{ }^{\circ} \mathrm{C}$ is the same, the yield is approximately the same at both temperatures. The yield was achieved $97 \%$ at reaction mole ratio $\left(\mathrm{nHBF}_{4} / \mathrm{nZnO}\right)$ of $3: 1$, temperature of $90{ }^{\circ} \mathrm{C}$, period of $90 \mathrm{~min}$. and stirring rate of $300 \mathrm{rpm}$. Under the optimum conditions, the speed range of the magnetic stirrer was changed from 300 to $500 \mathrm{rpm}$ and experiments were carried out separately. The yield was unchanged and recorded as $97 \%$. Synthetic and commercial zinc fluoroborate samples were tried to analyze by XRD instrument. Both of them decomposed during the XRD analysis. There is no XRD pattern of zinc fluoroborate in the literature and instrument software (Aydın et al., 2019).

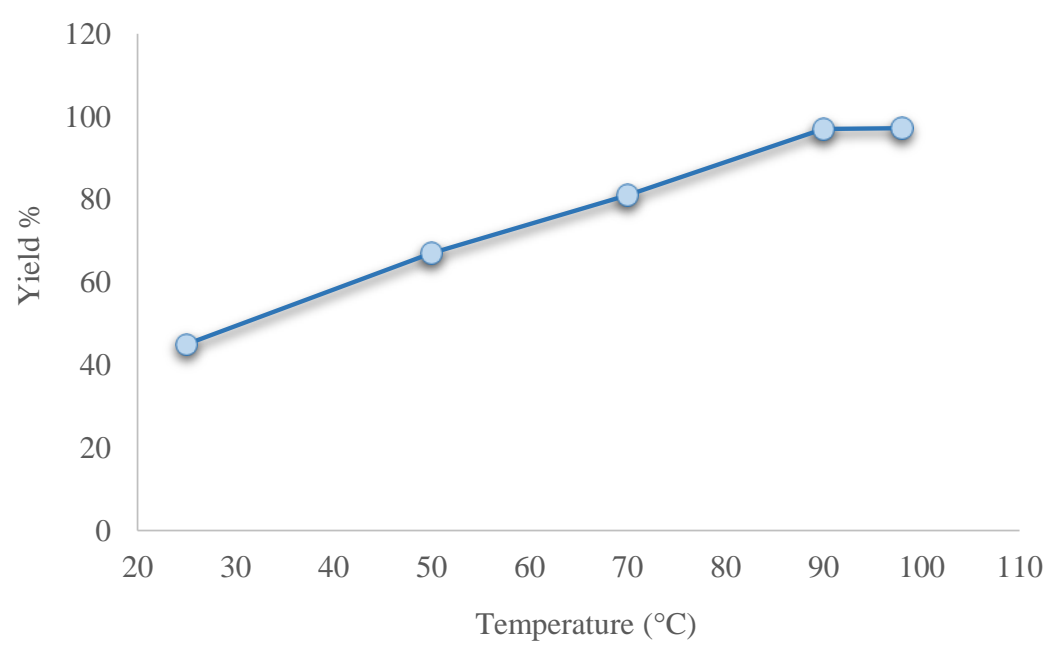

Figure 4. Effect of temperature on the product yield $\left(\mathrm{n}_{\mathrm{HBF}} / \mathrm{n}_{\mathrm{ZnO}}=3: 1,90 \mathrm{~min}, 300 \mathrm{rpm}\right)$

The samples were taken from the reaction medium and diluted periodically at three different temperatures to find optimum reaction period. $\mathrm{BF}_{4}^{-}$ion concentration was determined by using ion selective electrode. The time dependent variation of concentration was given in Figure 5. 


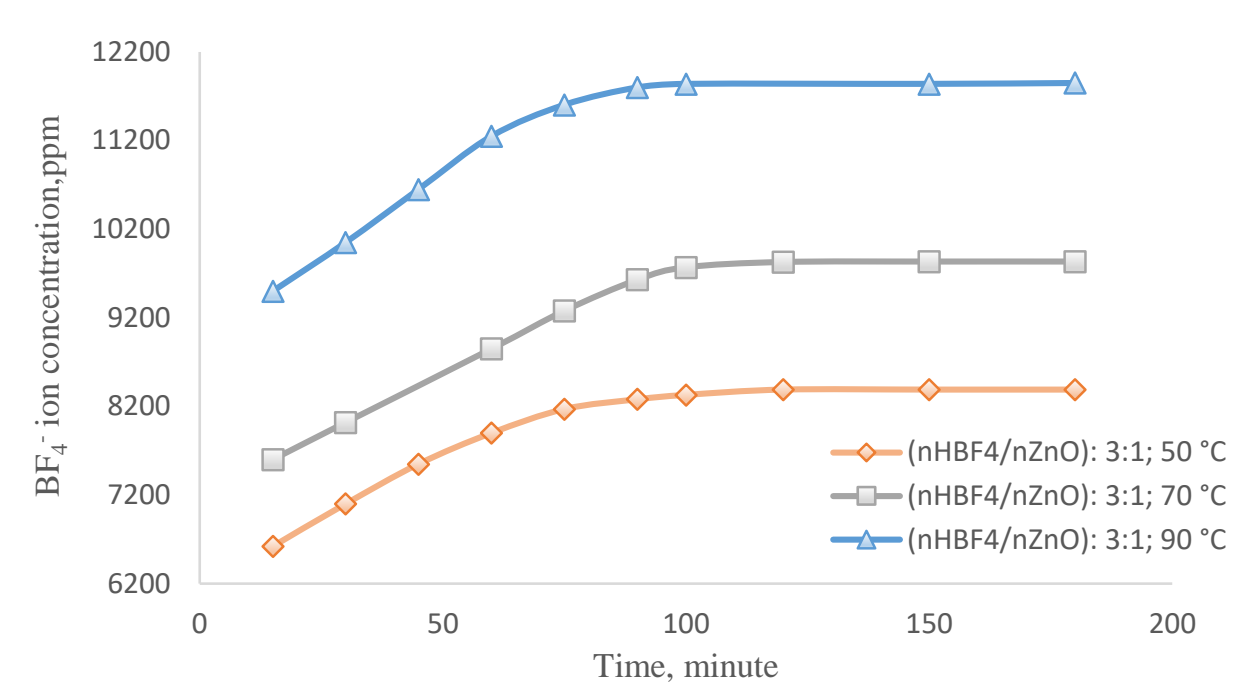

Figure 5. The change of $\mathrm{BF}_{4}^{-}$ion concentration with the time at different temperatures $\left(\left(\mathrm{nHBF}_{4} / \mathrm{nZnO}\right)=3: 1,90 \mathrm{~min}, 300 \mathrm{rpm}\right)$

Figure 5 shows that the fluoroborate ion concentration varies with temperature and reaction time. As the temperature and time increase, the fluoroborate ion concentration observed in the reaction medium increases. After a certain time, the fluoroborate ion concentration in the reaction medium is fixed. Figure 5 also illustrates that fluoroborate ion concentration was fixed faster at $90{ }^{\circ} \mathrm{C}$ than at other operating temperatures. After 90 minutes, the concentration remained constant at $90^{\circ} \mathrm{C}$. Short reaction time may be chosen if the reaction would be easily accomplished. 90 minutes was chosen optimum reaction time. Commercial and synthetic zinc fluoroborate were compared by means FTIR analysis. FTIR spectra of products synthesized at $90{ }^{\circ} \mathrm{C}$ and $98^{\circ} \mathrm{C}$ and commercial zinc fluoroborate are given in Figure 6. Characteristic FTIR absorption band of B-F is $1000-1100 \mathrm{~cm}^{-1}$ range (Leoni et al., 1991). Figure 6 shows that the FTIR peaks of the commercial zinc fluoroborate and the synthetic zinc fluoroborate overlap. 


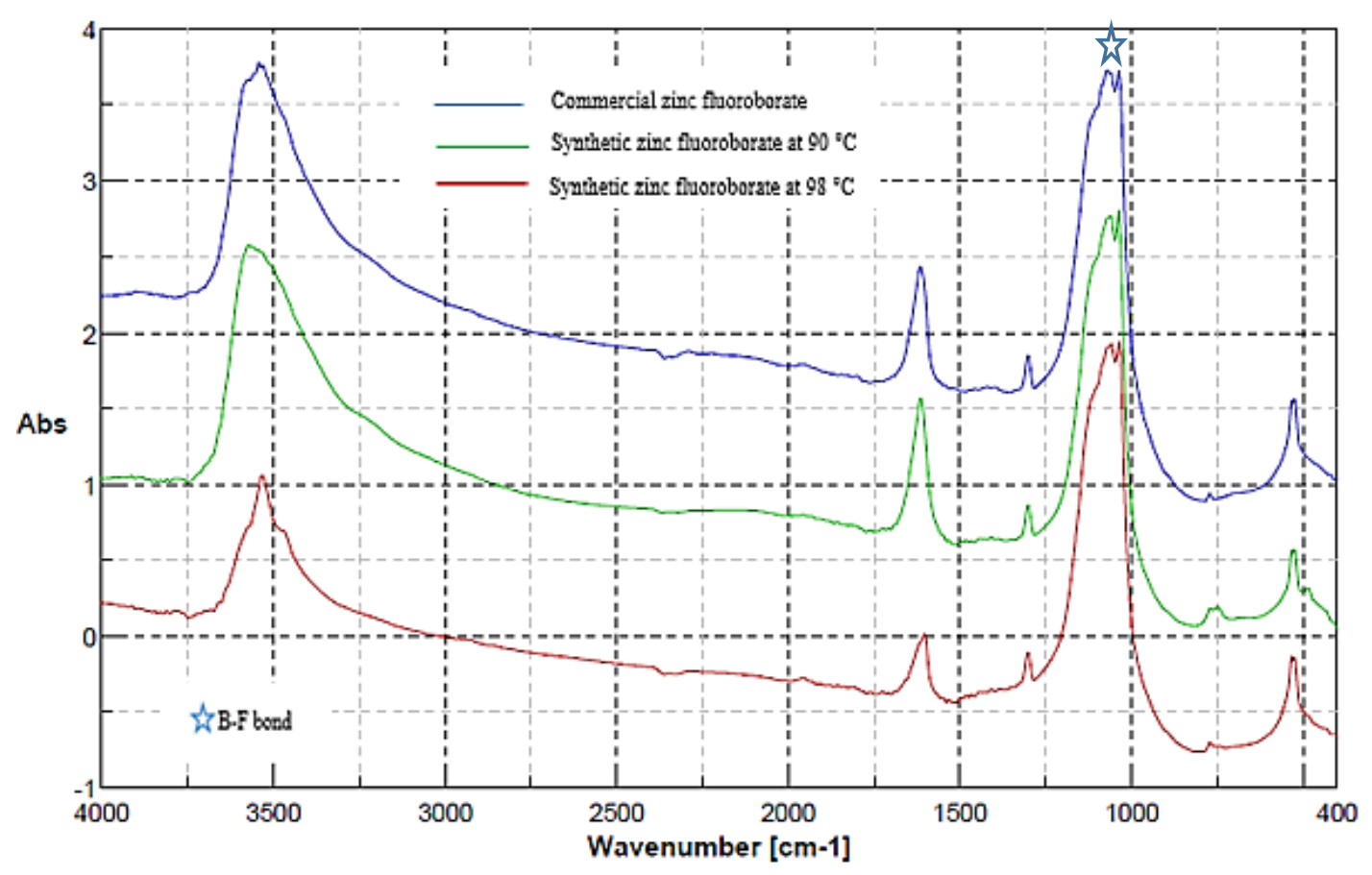

Figure 6. FTIR patterns of commercial zinc fluoroborate and synthetic zinc fluoroborate (produced at optimum conditions)

Purity of product was found by using calibration graph of commercial zinc fluoroborate. The solutions were prepared by using different amounts of commercial zinc fluoroborate. $\mathrm{BF}_{4}^{-}$ion concentration of solutions was found by using $\mathrm{BF}_{4}^{-}$ion selective electrode. Calibration graph of zinc fluoroborate was given in Figure 7.

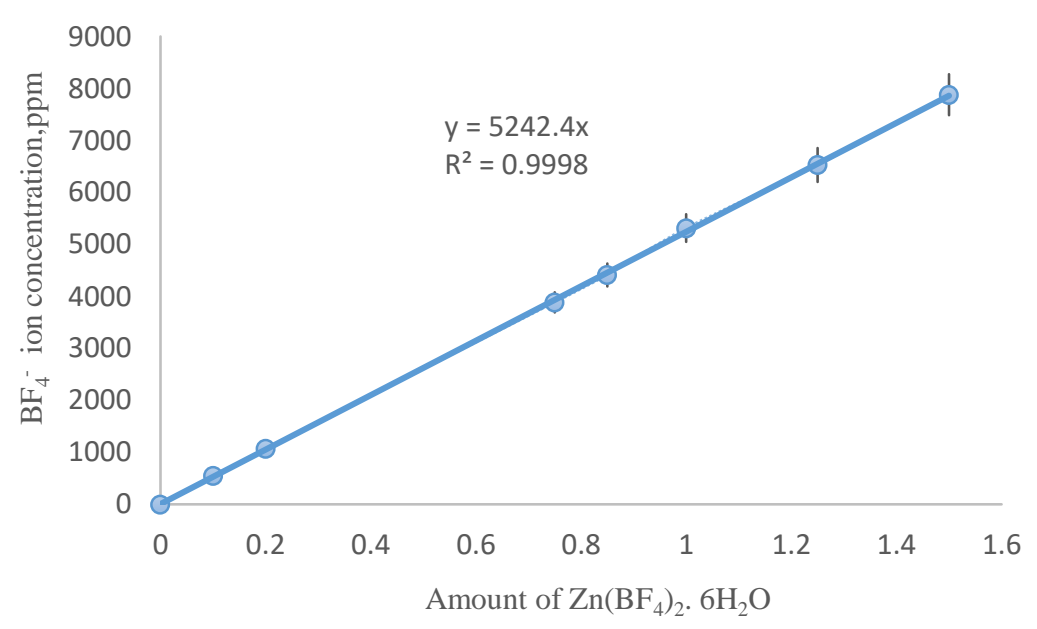

Figure 7. The calibration curve of commercial zinc fluoroborate 
Zinc fluoroborate was synthesized $98 \%$ purity in optimum conditions $\left(\mathrm{n}_{\mathrm{HBF} 4} / \mathrm{n}_{\mathrm{ZnO}}=3: 1 ; 90{ }^{\circ} \mathrm{C}\right.$; 300 rpm; 90 min.).

The flame retardancy of the samples was characterized by the limiting oxygen index test (LOI). Atmospheric air contains about $21 \%$ oxygen. A material with a LOI value less than 21 burns very easily. The LOI value of a slow burning material is expected to be greater than $21 \%$ but less than $28 \%$. A self-extinguishing material has a LOI greater than $28 \%$ and will stop burning after the ignition source has been removed. There is a relationship between LOI and the characteristics of the material such as heat dissipation rate, smoke density and total heat release (Friedrich and Breuer, 2015). The LOI tests of impregnated fabrics with zinc fluoroborate solutions of $15 \%, 30 \%$, and 50\% were carried out according to ASTM D 2863 standard. LOI results were compared with LOI value of original fabric. The impregnation of a flame-retardant solution is usually preferred to surface treatment because it penetrates below the surface to provide a more effective protection, and its effect is longer lasting (Tondi et al., 2014). Fabrics were the same size and properties. The LOI values were given in Table 2.

Table 2. LOI values of untreated and zinc fluoroborate impregnated fabrics (at different concentrations

\begin{tabular}{lc}
\hline Fluoroborate concentration, $\%$ & LOI , $\mathrm{O}_{2} \%$ \\
\hline Untreated Fabric & 16 \\
$15 \%$ solution impregnated fabric & 28 \\
$30 \%$ solution impregnated fabric & 45 \\
$50 \%$ solution impregnated fabric & $>55$ \\
\hline
\end{tabular}

LOI value of $50 \%$ zinc fluoroborate solution impregnated fabric was above $55 \%$. This value is the maximum oxygen amount for limiting oxygen chamber instrument. A high LOI value indicates that the material is harder to burn under atmospheric conditions. A considerable 
increase in LOI result was seen when zinc fluoroborate was impregnated to the cotton fabric. The increase in the LOI value indicates that the addition of zinc fluoroborate significantly improves the flame retardancy of the cotton fabrics.

The resistance of the fabrics to high temperature was observed with high temperature durability tests. Original untreated fabric and 50\% zinc fluoroborate solution impregnated fabric were exposed to high temperature $\left(120,200\right.$ and $\left.250{ }^{\circ} \mathrm{C}\right)$. The imagines of fabric samples at the end of the experiments were shown in Figure 8.

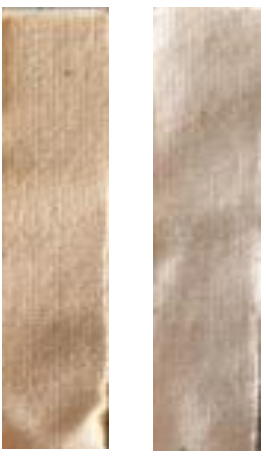

(a)

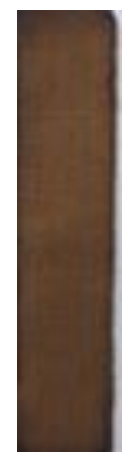

(b)

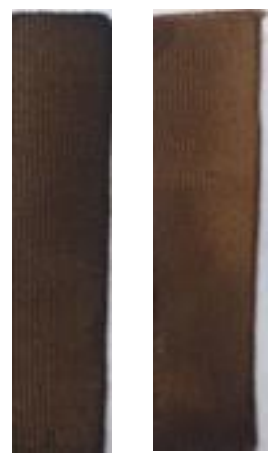

(c)

Figure 8. The imagines of untreated and zinc fluoroborate impregnated fabrics after high temperature durability tests (a) $120{ }^{\circ} \mathrm{C}$ (b) $200{ }^{\circ} \mathrm{C}$ (c) $250{ }^{\circ} \mathrm{C}$

Figure 8 shows that the color changes from pale yellow to dark brown on the fabrics, gradually. In this test, it was seen that color change of untreated original fabric was more than zinc fluoroborate solution impregnated fabric when they were exposed the high temperatures. High temperature test results reveal that the zinc fluoroborate impregnated fabric has better resistance to high temperature than the untreated original fabric.

\section{CONCLUSION}

Zinc fluoroborate has been synthesized by wet method, an economical process, using zinc oxide and fluoroboric acid with $97 \%$ yield and $98 \%$ purity. We investigated effects of reactant ratio, temperature, stirrer rate, reaction period on the yield. The maximum product yield was obtained 
at the reactant ratio $\left(\mathrm{nZnO} / \mathrm{nHBF}_{4}\right)$ of $1: 3$, the temperature of $90{ }^{\circ} \mathrm{C}$, reaction period of 90 minutes and stirrer rate of $300 \mathrm{rpm}$. The flame retardancy effect of zinc fluoroborate on cotton fabric was determined by LOI and high temperature durability test. LOI result of zinc fluoroborate impregnated fabric was found above $55 \%$. The color change of the original untreated fabric when exposed to high temperature was more than the zinc fluoroborate impregnated fabric. Zinc fluoroborate enhanced the resistance of the cotton fabric to high temperature. These results imply that zinc fluoroborate exhibits excellent flame retardancy effect for cotton fabrics and it is candidate to be impressive flame retardant for cotton fabrics.

\section{ACKNOWLEDGEMENTS}

This work was supported by Eti Mine Works General Managements under project number 2014.C.11.0010.15. The authors are grateful to Eti Mine Works of Turkey for financial support and Gazi University for laboratory facilities usage.

\section{REFERENCES}

Achilonu, M.C. \& Umesiobi, D.O. 2010. The formation of carbon-carbon and carbonheteroatom bonds using silver tetrafluoroborate as a promoter. Arabian Journal of Chemistry, 9(2): 1984-2003

Ayar, B., Gürü, M. \& Çakanyıldırım, Ç. 2014. Solid phase synthesis of anhydrous zinc borate from zinc and boron oxide and utilization as a flame retardant in dye and textile. Gazi University Journal of Science, 27(3): 987-991.

Aydın, Y.D., Gürü, M., İpek, D. \& Özyürek, D. 2019. Obtainment of copper(II) fluoroborate by high-energy impacted ball-milling. Acta Physica Pololonica A, 135: 888-891. 
Aydın, Y.D., Gürü, M., Ipek, D. \& Özyürek D. 2017. Synthesis and characterization of zinc fluoroborate from zinc fluoride and boron by mechanochemical reaction. Arabian Journal of Science and Engineering, 42: 4409-4416.

Booth, H.S. \& Martin, D.R. 1949. Boron Trifluoride and Its Derivatives, Wiley, Newyork.

Bourbigot, S., Bras, M.L., Leeuwendal, R., Shenc, K.K. \& Schubertc, D. 1999. Recent advances in the use of zinc borates in flame retardancy of EVA. Polymer Degradation and Stability, 64(3): 419-425.

Ceyhan, A.A., Bağcı, S., Baytar O., \& Şahin Ö. 2020. Ammonium fluoroborate production and determination of production parameters. Journal of Boron, 5(2): 6372

Chen, P.Y. \& Sun, I.W. 1999. Electrochemical study of copper in a basic 1-ethyl-3 methylimidazolium tetrafluoroborate room temperature moleten salt. Electrochimica Acta, 45(3): 441-450.

Dogan, M. \& Unlu, M. 2014. Flame retardant effect of boron compounds on red phosphorus containing epoxy resins. Polymer Degradation and Stability, 99(2014): 12-17.

Fidell, L.I. \& Brook, B. 1971. Fire-resistant finish for textiles comprising zinc fluoroborate, Patent US 357734.

Friedrich, K. \& Breuer, U. 2015. Multifunctionality of polymer composites: challenges and new solutions. Elsevier, United States of America.

Ibrahim, S., Elbatal, F.H. \& Abdelghany, A. 2016. Optical character enrichment of $\mathrm{NdF}_{3}-$ doped lithium fluoroborate glasses. Journal of Non-Crystalline Solids, 453: 16-22. 
Kasem, M.A. \& Richard, H.R. 1972. Flame-retardants for fabrics- function of boroncontaining additives. Industrial \& Engineering Chemistry Product Research and Development, 11(2): 114-133.

Leoni, P., Sommovigo, M., Pasqualli, M., Midollini, S., Braga, D. \& Sabatino, P. 1991. Coordinated water/anion hydrogen bonds and $\mathrm{Pd}-\mathrm{H}$ bond acidity in cationic palladium(II) aquo hydrides and the x-ray crystal and moleecular structures of trans$\left[\left(\mathrm{Cy}_{3} \mathrm{P}\right)_{2} \mathrm{Pd}(\mathrm{H})\left(\mathrm{H}_{2} \mathrm{O}\right)\right] \mathrm{BF}_{4}(\mathrm{Cy}=$ cyclohexyl). Organometallics. 10(4): 1038-1044.

Liu, Y. \& Pritzker, M. 2003. Effect of pulse plating on composition of $\mathrm{Sn}-\mathrm{Pb}$ coatings deposited in fluoroborate solutions. Journal of Applied Electrochemistry, 33(12): 1143-1153.

Lu, S.Y. \& Hamerton, I. 2002. Recent developments in the chemistry of halogen-free flame retardant polymers. Progress in Polymer Science, 27(8): 1661-1712.

Papcun, J.R. 2000. Fluorine compounds, inorganic, fluoroboric acid and fluoroborates. "In: Kirk-Othmer Encyclopedia of Chemical Technology, Wiley, New York.

Park, S. \& Kim, K. 2017. Tetramethylammonium tetrafluoroborate: The smallest quaternary ammonium tetrafluoroborate salt for use in electrochemical double layer capacitors. Journal of Power Sources, 338: 129-135.

Prajnashree, M., Wagh, A., Sangeetha, B. \& Kamath, D.S. 2013. Characterization of $\operatorname{Pr}_{6} \mathrm{O}_{11}$ doped zinc fluoroborate glass. European Scientific Journal, 9(18): 83-92.

Pujala, B., Rana, S. \& Chakraborti, A.K. 2011. Zinc tetrafluoroborate hydrate as a mild catalyst for epoxide ring opening with amines: scope and limitations of metal tetrafluoroborates and applications in the synthesis of antihypertensive drugs $(\mathrm{RS}) /(\mathrm{R}) /(\mathrm{S})$-metoprolols. The Journal of Organic Chemistry, 76(21): 8768-878. 
Ranu, B.C., Jana, U. \& Majee, A. 1999. A simple and efficient method for selective deprotection of t-butyldimethylsilyl ethers by zinc tetrafluoroborate in water. Tetrahedron Letters, 40(10): 1985-1988.

Rayappan, I.A. \& Marimuthu, K. 2013. Structural and luminescence behavior of the $\mathrm{Er}^{3+}$ doped alkali fluoroborate glasses. Journal of Non-Crystalline Solids, 367: 43-50.

Rayappan, I.A., Marimuthu, K., Babu, S.S. \& Sivaraman, M. 2010. Concentration dependent structural, optical and thermal investigations of $\mathrm{Dy}^{3+}$-doped sodium fluoroborate glasses. Journal of Luminescence, 130(12): 2407-2412.

Sarkar, A., Santra, S., Kundu, S.K., Ghosal, N.C., Hajra, A. \& Majee, A. 2015. Zinc tetrafluoroborate: a versatile and robust catalyst for various organic reactions and transformations. Synthesis, 47: 1379-1386.

Tondi, G., Haurie, L., Wieland, S., Petutschnigg, A., Lacasta, A., Monton, J. 2014. Comparison of disodium octaborate tetrahydrate-based and tanninboron- based formulations as fire retardant for wood structures. Fire and Materials, 38(3): 381-390.

Wagh, A., Raviprakash, Y. \& Kamath, S.D. 2017. Gamma rays interactions with $\mathrm{Eu}_{2} \mathrm{O}_{3}$ doped lead fluoroborate glasses. Journal of Alloys and Compounds, 695: 27812798.

Wang, X., Song, Y. \& Bao, J. 2010. Synergistic effects of $\mathrm{ZrO}_{2}$ or $\mathrm{B}_{2} \mathrm{O}_{3}$ on flame-retarded poly (butyl methacrylate) with tricresylphosphate. Fire and Materials, 34(7): 357366.

Wilkie, C.A. \& Morgan, A.B. 2009. Fire retardancy of polymeric materials. 2nd ed., CRC Press, Boca Raton.

Zhang, S.S.; Xu, K. \& Jow, T.R. 2002. Study of $\mathrm{LiBF}_{4}$ as an electrolyte salt for a li-ion battery. Journal of The Electrochemical Society, 149(5): A586-A590. 